\title{
Nutrition Module Intervention to Improve Nutrition Knowledge, Attitude and Practice of Trainers for Persons with Disabilities in Rehabilitation Centers in Malaysia
}

Chen $\mathrm{ST}^{1 *}$, Soo $\mathrm{KL}^{2}$, Azriani $\mathrm{AR}^{3}$, Van Rostenberghe $\mathrm{H}^{4}$, Sakinah $\mathrm{H}^{1}$

${ }^{1}$ Dietetics Program, School of Health Sciences, Health Campus, UniversitiSains Malaysia, 16150 KubangKerian, Kelantan, Malaysia.

${ }^{2}$ Nutrition Program, School of Health Sciences, Health Campus, UniversitiSains Malaysia, 16150 KubangKerian, Kelantan, Malaysia.

${ }^{3}$ Department of Community Medicine, School of Medical Sciences, Health Campus, UniversitiSains Malaysia, 16150 KubangKerian, Kelantan, Malaysia.

${ }^{4}$ Department of Paediatrics, School of Medical Sciences, Health Campus, UniversitiSains Malaysia, 16150 KubangKerian, Kelantan, Malaysia.

\begin{abstract}
Introduction: Other than parents, primary care providers such as community workers and rehabilitation service personnel are also important nutritional gatekeepers for persons with disabilities (PWD). Good nutrition management for PWD by joint efforts is most desirable to prevent further disablement in later years. This study aimed to evaluate the effectiveness of a nutrition module intervention on improving trainers' knowledge, attitude and practice in nutrition management for PWD in rehabilitation centres.
\end{abstract}

Methods: This quasi-experimental study which employed mixed methods design recruited 45 trainers as intervention group and another 42 trainers as comparison group. Intervention group participated in a three-consecutive-day nutrition intervention while comparison group was trained on general health care services for PWD. Nutrition knowledge, attitude and practice scores for both groups were assessed using a validated questionnaire at baseline (T0), 1-month (T1) and 6-month (T2) intervals after intervention. Intervention trainer's on-the-job nutrition practice was further assessed by qualitative interviews.

Results: Repeated measures ANCOVA demonstrated that intervention group attained significantly higher nutrition knowledge $(p<0.001)$ and practice $(p=0.001)$ scores than comparison group at T1 (mean difference for knowledge $=6.95$; mean difference for practice $=2.93$ ) and T2 (mean difference for knowledge $=10.30$; mean difference for practice $=4.78$ ). Significant higher nutrition attitude $(p=0.004)$ score for intervention group was observed at T2 (mean difference $=3.08)$.

Conclusion: This program produced favourable outcome on improving nutrition knowledge, attitude and practice of rehabilitation service personnel. The nutrition module is certainly relevant to serve as an educational or reference material for care providers of PWD in Malaysia.

Keywords: Attitude; Disability; Education; Knowledge; Nutrition; Practice; Trainer.

\section{*Corresponding Author:}

Seong-Ting Chen,

Dietetics Program, School of Health Sciences, Health Campus, UniversitiSains Malaysia, 16150 KubangKerian, Kelantan, Malaysia.

Tel: +6097677556

Fax: +6097677515

E-mail: stchen@usm.my

Recieved: January 11, 2015

Accepted: January 23, 2015

Published: January 28, 2015

Citation: Chen ST et al., (2015). Nutrition Module Intervention to Improve Nutrition Knowledge, Attitude and Practice of Trainers for Persons with Disabilities in Rehabilitation Centers in Malaysia. Int J Food Sci Nutr Diet. 04(1), 183-189. doi: http://dx.doi.org/10.19070/23263350-1500034

Copyright: Chen ST $^{\odot}$ 2015. This is an open-access article distributed under the terms of the Creative Commons Attribution License, which permits unrestricted use, distribution and reproduction in any medium, provided the original author and source are credited.

\section{Introduction}

Persons with disabilities (PWD) are individuals who experience long term physical, mental, intellectual or sensory disablement leading to barriers that impede them from full and effective participation in society. Population with disabilities accounts for a significant portion of world population. More than one billion people in the world (15\% of the global population) are having some forms of disability [1]. And, approximately $20 \%$ of them experience substantial difficulties in functioning. In Malaysia, an estimated 2.8 million people live with various forms of disability. More than 850 thousand children below 15 years (10\% of the Malaysian children population) have a disability and at least one third of them are severe.

In spite of robust healthcare strategies and disability rights movement, PWD are still prevalent to poor health. Malnutrition, either under-nutrition or over-nutrition, is evident among PWD. Among children and adolescents with disabilities, underweight prevalence 
in a range of $5 \%$ to $30 \%$ had been recorded in France (5.4\%) [2], Chile (10.8\%) [3] and Taiwan (28.1\%) [4]. Besides, more than onethird of these children were also found to be overweight or obese, as reported in the United Kingdom (33\%) [5], Taiwan $(37.7 \%$ ) [4], Chile (38.7\%) [3] and the United States (55.1\%) [6]. In addition, Bhaumik et al. (2008) [7], Melville et al. (2007) [8] and Wong (2011) [9] presented that half to two-third of the adult population with disabilities in the United Kingdom and Hong Kong were suffering from this double burden of malnutrition $(69.7 \%, 67.3 \%$ and $52.7 \%$, respectively). As in Malaysia, a study conducted in the poorest and most rural state- Kelantan documented a prevalence of $20.3 \%$ of the community-dwelling disabled people who were underweight while $22.7 \%$ who were overweight or obese [10].

Various literatures on disability have described that care giving for PWD is no longer the sole concern of parents and health professionals; it is also relevant to other primary care providers such as the community workers and rehabilitation service personnel [7]. They can become important nutritional gatekeepers or agents of change for the PWD. Good nutrition management for PWD by joint efforts that start early is most desirable to prevent further disablement in later years. Hence, nutrition education targeted at trainers and other care providers particularly those institutions that prepare meals for students, is imperative [11,12].

Community-based rehabilitation (CBR) is a multi-sectoral strategy to promote rehabilitation, equalization of opportunities, reduction of poverty and social inclusion for children and adults with disabilities within the general community development. It aims to generate culturally sensitive and appropriate rehabilitation services by using local facilities. In Malaysia, CBR centers provide rehabilitation services for PWD who are too young, too severely disabled and rejected by the special education mainstream. The trainers play a significant role in training and preparing meals for the PWD as well as supporting the parents in taking care of their children. Nonetheless, trainers in CBR centers are recruited on voluntary basis; no certification on special education endorsement, early intervention for children with disabilities or elementary education is required. Though periodical training programs are provided to the trainers after recruitment, there is still lack of proper and consistent nutrition education programs available to them. Insufficient nutrition knowledge results in trainers experience challenges in healthy food preparation for the PWD. Hence, the objective of this study was to evaluate the effectiveness of nutrition module intervention on improving trainers' knowledge, attitude and practice in nutrition management for PWD in CBR centers in Malaysia.

\section{Methods}

\section{Study Design and Subjects}

This study was conducted from October 2011 to July 2012 and it adopted the mixed methods quasi-experimental study design. Based on the standard deviation for knowledge, attitude and practice scores from a pilot study [13], the estimated sample size for each group was 44 trainers after considering a study power of $80 \%$, a significant level set at $5 \%$ for two-sided test, a detectable difference of 2.7 and an addition of $20 \%$ drop-out. Trainers from CBR centers in Kelantan (a state located at the north-eastern corner of Peninsular Malaysia) were chosen as the intervention group while trainers from CBR centers in Terengganu (a neighboring state) as the comparison group. Trainers who fulfilled the inclusion criteria and returned informed consents were recruited into the study. A total of 45 trainers from CBR centers in Kelantan were enrolled as the intervention group while 42 trainers from CBR centers in Terengganu as the comparison group. This study included all rehabilitation centers from the above two states of Malaysia; however, only one representative from each center was allowed to participate in the study due to insufficient of man power for care service in the centers. The study protocol was approved by The Research Ethics Committee (Human) Universiti Sains Malaysia and Malaysia Department of Social Welfare.

\section{Description of the Intervention}

"Nutrition Module for Trainers of Persons with Disabilities" was developed by the research team to serve as the intervention framework. This module documented eight general and specific PWD nutrition topics and was meant for a three-consecutive-day program. Figure 1 outlines the topics and contents of the nutrition module. This intervention which took approximately six hours per day employed the learner-centered approach. All sessions were delivered in the form of interactive lectures using Malay language. Each session commenced with introduction of learning outcomes and followed by content presented in lists of messages. Various creative teaching materials were introduced during lectures and these included food pyramid and food models, adaptive feeding utensils and teaching aids for PWD. Demonstrations on proper procedures to measure body weight and height; techniques to feed children with eating problems; and making of pictorial eating time table, flash card and board game to guide children with aversive mealtime behaviors, were provided. This intervention also emphasized the behaviorally focused approach as the ultimate aim was to improve trainers' nutrition management for PWD in the CBR centers. Each lecture was followed by an interactive learning activity such as quiz, group discussion on case study, role play or cooking session. The comparison group also received a three-day training program but focused on general health issues during care service for PWD. The comparison group only received the nutrition education at the end of the study where the intervention effect was not evaluated.

\section{Outcome Measures}

Kirkpatrick's Evaluation Model [14] was applied as the framework to determine the effectiveness of this nutrition intervention. Level 1- Reaction of Kirkpatrick's model measures the participants' acceptance or satisfaction level towards the intervention program; Level 2- Learning measures the extent of improvement in knowledge, attitudes or skills following the intervention; Level 3- Behavior assesses the transfer of learning to on-the-job practice.

Level 1- Reaction assessment was only applicable to the intervention group as it evaluated the participants' acceptance towards the nutrition intervention. Data was collected at the end of the three-day program using training evaluation rating sheet. Level 2- Learning and Level 3- Behavior were assessed using a validated questionnaire, Nutrition Knowledge, Attitude and Practice Questionnaire about Persons with Disabilities (KAP-nOKU) [13]. KAP-nOKU was a guided self-administered questionnaire and the possible scores ranged from 0 to 29 for knowledge, 13 to 65 for attitudes and 15 to 75 for practice domains, respectively. Kuder-Richardson 20 for knowledge domain was 0.63; while Cronbach's alpha values for attitude and practice domains were 0.67 and 0.82 [13]. KAP-nOKU was administered at baseline (T0) for 
Figure 1. Outline of Nutrition Module for Trainers of Persons with Disabilities.

\begin{tabular}{|l|l|}
\hline Topic & Content \\
\hline Unit 1: Introduction of nutrients & -Nutrients, functions and food sources \\
\hline Unit 2: Food pyramid & $\begin{array}{l}\text {-Well-balanced diet and health risks of malnourishment } \\
\text {-Food pyramid; levels and food groups; number of servings and serving size of food for } \\
\text { each food group }\end{array}$ \\
\hline $\begin{array}{l}\text { Unit 3: Healthy eating and } \\
\text { lifestyle }\end{array}$ & -Nutrition and healthy lifestyle guidelines based on Malaysian Dietary Guidelines 2010 \\
\hline Unit 4: Healthy body weight & $\begin{array}{l}\text {-Body weight and height measurement; BMI calculation and classification } \\
\text {-Risk factors and side effects of underweight and overweight } \\
\text {-Guidelines on healthy body weight maintenance }\end{array}$ \\
\hline $\begin{array}{l}\text { Unit 5: Nutrition management } \\
\text { for persons with Down's syn- } \\
\text { drome }\end{array}$ & $\begin{array}{l}\text {-Identification of health and related nutrition problems in persons with Down's syndrome } \\
\text {-Guidelines on nutrition management }\end{array}$ \\
\hline $\begin{array}{l}\text { Unit 6: Nutrition management } \\
\text { for persons with cerebral palsy }\end{array}$ & $\begin{array}{l}\text {-Identification of health and related nutrition problems in persons with cerebral palsy } \\
\text {-Guidelines on nutrition management }\end{array}$ \\
\hline $\begin{array}{l}\text { Unit 7: Nutrition management } \\
\text { for persons with autism spec- } \\
\text { trum disorders }\end{array}$ & $\begin{array}{l}\text {-Identification of health and related nutrition problems in persons with autism spectrum } \\
\text { disorders } \\
\text {-Guidelines on nutrition management }\end{array}$ \\
\hline $\begin{array}{l}\text { Unit 8: Management of PWD's } \\
\text { aversive mealtime behaviors }\end{array}$ & $\begin{array}{l}\text {-Identification of causes leading to PWD's aversive mealtime behaviors } \\
\text {-Recommendations on problem solving }\end{array}$ \\
\hline
\end{tabular}

intervention and comparison groups. No immediate post-test of $\mathrm{KAP}-\mathrm{nOKU}$ was indicated. Two post-intervention assessments were only conducted at 1-month (T1) and 6-month (T2) intervals from baseline for both groups. No reinforcement of education was given to either group within these six months.

As part of the Level 3- Behavior assessment, a qualitative approach was added at the end of the study among a sub-sample of intervention group. This approach was intended to corroborate the quantitative findings of the self-reported practice measure of KAP-nOKU. Conventional content analysis was chosen as the qualitative research method to explore trainers' on-the-job nutrition practice for PWD in the CBR centers in Kelantan. Snowball sampling method was used to recruit trainers who attended the nutrition intervention and had completed the three KAP-nOKU assessments. Recruitment of participants progressed until data saturation occurred. A total of thirteen trainers participated in this qualitative study. Data were collected using face-to-face semistructured interviews. Open-ended questions were asked to gain deeper information and the main question was, what nutrition management or strategy for PWD have you practiced in the center? How did you do it? All conversations were audio-taped and field notes were taken. The interviews were then transcribed verbatim and referred back to the trainers for respondent validation.

\section{Data Analysis}

Quantitative data were analyzed using IBM SPSS Statistics version 19.0 (SPSS, Inc., Chicago, IL, USA, 2010). Repeated measures ANCOVA was performed to determine the difference of knowledge, attitude and practice scores between study groups with regard to time intervals. Baseline variable which was significantly different between groups was controlled in the model. P-value of less than 0.05 indicated statistical significance. As for qualitative data, interview transcripts were entered into NVivo Version 8 (QSR International Pty Ltd, Melbourne, Australia, 2008) for qualitative data organization. Inductive content analysis approach was adopted to identify themes. Finalized themes were translated from Malay to English for result presentation.

\section{Results}

All participants were women and Malays; their age ranged from 20 to 48 years (mean and $\mathrm{SD}=32.7$ and 8.0 ). The trainers' years of work experience ranged from 1 to 28 years (median and IQR= 5.0 and 5.0$)$. Three-quarters of them $(75.9 \%)$ were married and $80.5 \%$ of them attained highest educational level at upper secondary school. At baseline, trainers in both groups were not significantly different across socio-demographic variables such as age, marital status and educational level, except for work experience. The comparison group had significantly higher mean for years of work experience (mean difference $=+3.1$ ) than the intervention group ( $p=0.001)$. Nevertheless, there was no significant difference in baseline knowledge, attitude and practice scores between the two groups.

Level 1- Reaction. Overall, almost all trainers were satisfied with the content, materials, facilities and facilitators of the nutrition module intervention program. There was only a small group of trainers who were dissatisfied with the reference materials and notes given $(4.4 \%)$ and the food and beverages served $(8.9 \%)$. In brief, it can be concluded that trainers from the intervention group liked the nutrition module education program.

Level 2- Learning and Level 3- Behavior (Quantitative Data). A final sample of 37 trainers for intervention and comparison groups, respectively, completed all three KAP-nOKU assessments at T0, T1 and T2. After controlling numerical covariate (work experience) in the models, repeated measures ANCOVA showed that there were significant differences in nutrition knowledge $(\mathrm{F}=97.80, p<0.001)$, attitude $(\mathrm{F}=5.99, p=0.004)$ and practice $(\mathrm{F}=7.71, p=0.001)$ scores between intervention and comparison groups over the time period (Table 1). At T1, the mean knowledge and practice scores for intervention group were significantly increased and higher than the comparison group (mean difference for knowledge $=6.95$; mean difference for practice $=2.93$ ). Same observations were also noticed at T2 (mean difference for knowledge $=10.30$; mean difference for practice $=4.78)$. However, significant improvement in mean attitude score for interven- 
Table 1. Comparisons of knowledge, attitude and practice scores between intervention and comparison groups based on time

\begin{tabular}{|c|c|c|c|c|}
\hline & Time & Group & Mean scores & $95 \% \mathrm{CI}$ \\
\hline \multirow{6}{*}{ Knowledge } & \multirow{2}{*}{ T0 } & Intervention & 13.67 & $12.49,14.85$ \\
\hline & & Comparison & 15.57 & $14.40,16.75$ \\
\hline & \multirow{2}{*}{ T1 } & Intervention & $23.95^{*}$ & $22.85,25.05$ \\
\hline & & Comparison & 17.00 & $15.90,18.09$ \\
\hline & \multirow{2}{*}{$\mathrm{T} 2$} & Intervention & $26.56^{*}$ & $25.44,27.67$ \\
\hline & & Comparison & 16.26 & $15.14,17.37$ \\
\hline \multirow{6}{*}{ Attitude } & \multirow{2}{*}{ T0 } & Intervention & 50.90 & $49.59,52.21$ \\
\hline & & Comparison & 51.29 & $49.98,52.60$ \\
\hline & \multirow{2}{*}{$\mathrm{T} 1$} & Intervention & 53.03 & $51.63,54.43$ \\
\hline & & Comparison & 52.27 & $50.87,53.67$ \\
\hline & \multirow{2}{*}{$\mathrm{T} 2$} & Intervention & $54.18^{*}$ & $52.56,55.79$ \\
\hline & & Comparison & 51.10 & $49.48,52.71$ \\
\hline \multirow{6}{*}{ Practice } & \multirow{2}{*}{ T0 } & Intervention & 47.66 & $46.60,48.73$ \\
\hline & & Comparison & 47.55 & $46.49,48.62$ \\
\hline & \multirow{2}{*}{ T1 } & Intervention & $50.67 *$ & $49.44,51.90$ \\
\hline & & Comparison & 47.74 & $46.51,48.97$ \\
\hline & \multirow{2}{*}{$\mathrm{T} 2$} & Intervention & $52.25^{*}$ & $50.75,53.76$ \\
\hline & & Comparison & 47.47 & $45.97,48.99$ \\
\hline
\end{tabular}

Figure 2 (a). Adjusted mean knowledge scores at baseline, 1 month and 6 months from baseline.

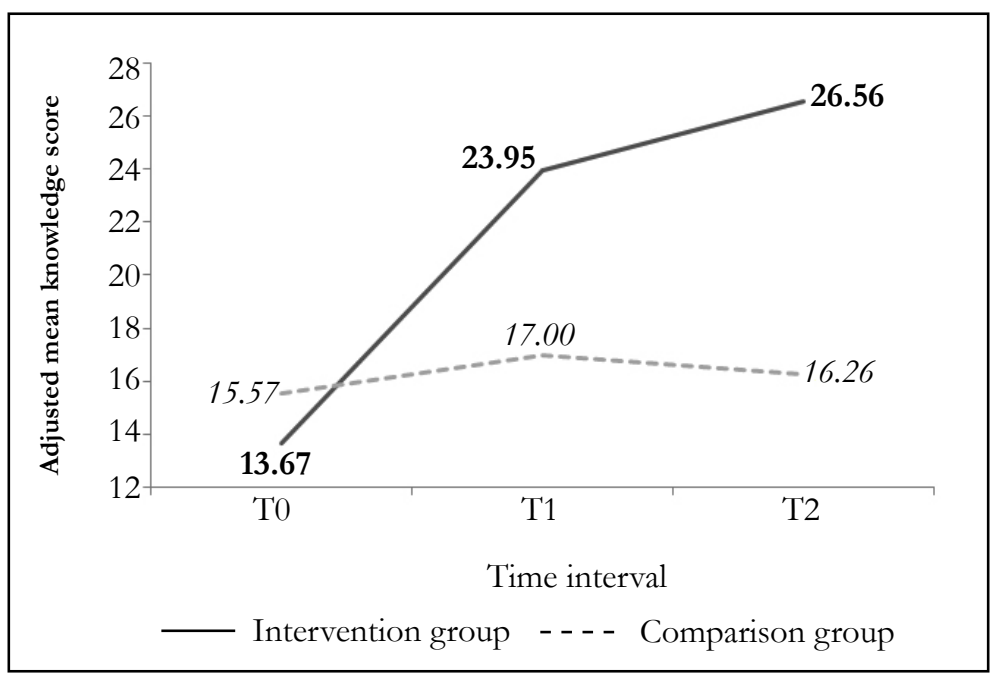

Figure 2 (b). Adjusted mean attitude scores at baseline, 1 month and 6 months from baseline

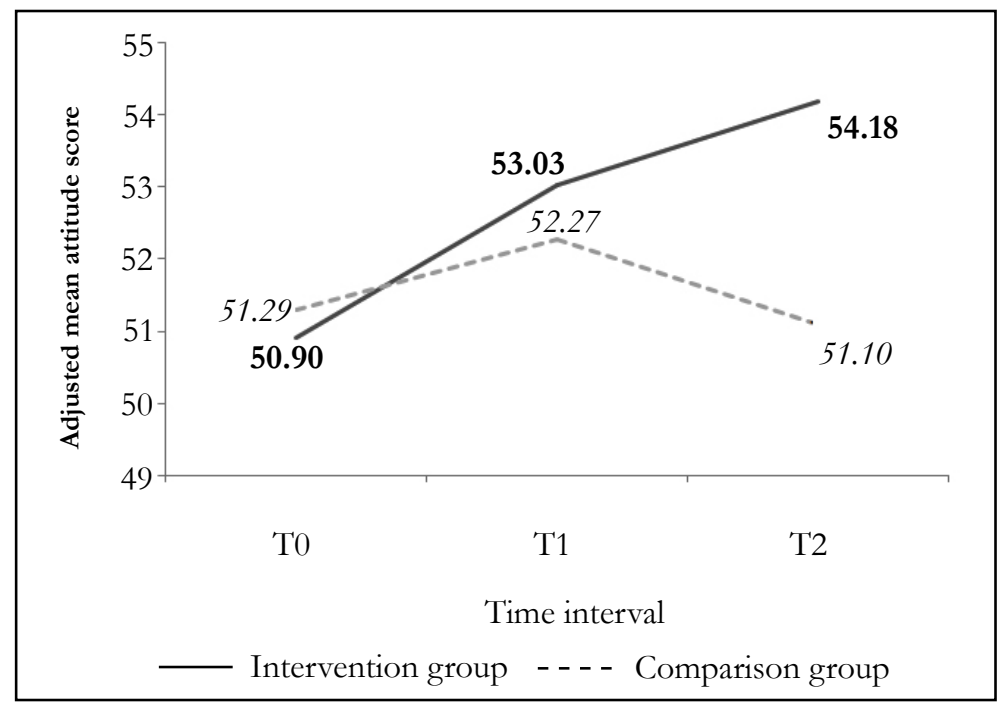


Figure 2(c). Adjusted mean practice scores at baseline, 1 month and 6 months from baseline.

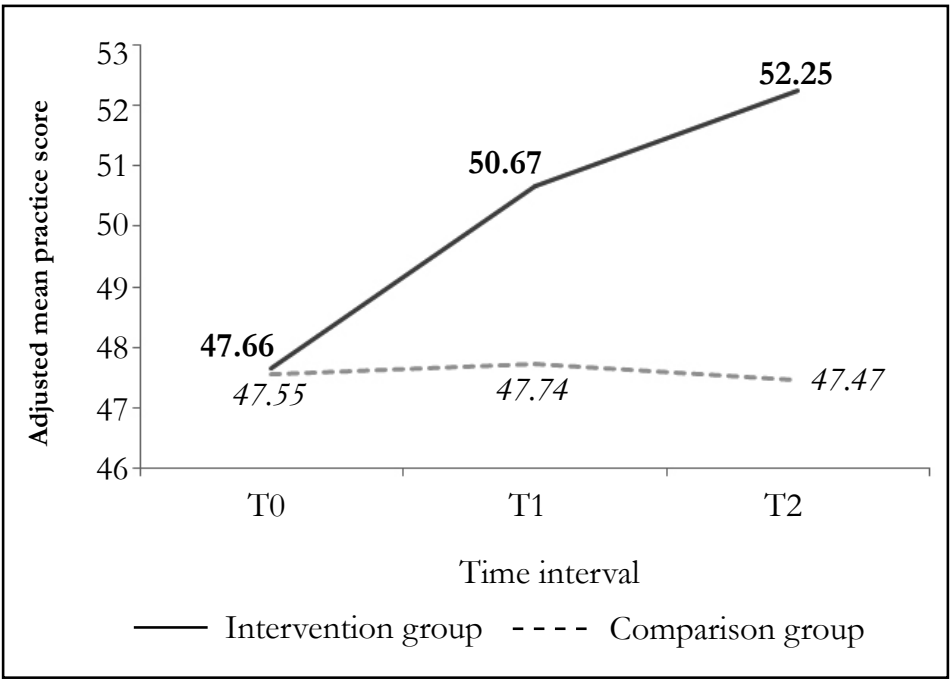

tion group as compared to comparison group was only observed at T2 (mean difference $=3.08$ ). Figures $2(\mathrm{a}), 2(\mathrm{~b})$ and $2(\mathrm{c})$ illustrate the adjusted mean knowledge, attitude and practice scores for intervention and comparison groups at baseline, 1 month and 6 months from baseline.

Level 3- Behavior (Qualitative Data). Four main themes emerged to address the trainers' on-the-job nutrition management for PWD in CBR centers in Kelantan following the nutrition intervention.

\section{Theme 1: Food preparation for PWD}

The trainers reported that the major change in practice was the adoption of more healthful cooking method. Most of them $(n=9)$ mentioned that they had changed from high fat food preparation to low-fat cooking, as one trainer stated "Last time I used to fry... since we learn (the healthy cooking methods), like steam, boil...soup, now we have (practiced) all these" (Trainer, T12, age 24, 3 years work experience). Some trainers also discussed that they had reduced the use of salt or seasonings $(n=6)$ and sugar $(n=4)$ during food preparation for the PWD. After gaining the knowledge on food pyramid, message on well-balanced meal preparation was greatly valued $(n=9)$. The trainer (T5, age 27, 6 years work experience) mentioned she would make sure that the meals prepared for the PWD must comprise of rice (or noodles), meat or chicken, vegetables and also fruits; in which this practice was not stressed on during days prior to the program especially for vegetables and fruits. In addition, some trainers $(n=6)$ also stated that they had tried to process the food for those with eating difficulties in which last time they thought these PWD had chewing and swallowing problems and they never be offered hard-textured food especially the protein sources.

\section{Theme 2: Response to PWD's aversive mealtime behaviors}

Aversive mealtime behaviors such as taking others' food instead of eating own food or disturbing others while they are eating, are common among PWD in CBR centers. Most trainers $(n=8)$ mentioned that they would advise the PWD at once to avoid them to continue such behaviors. A few trainers $(n=3)$ admitted that previously they used to provide additional food to those who behave negatively in order to prevent quarrels among the PWD. Since they learned that the PWD were needed to be informed of the rules and trained on the good manners at dining table, giving ad- vice on the spot was practiced. Besides giving advice, the trainers $(n=6)$ also mentioned that they would implement punishments to those who misbehaved. She explained "...fighting during lunch...I ask them to sweep the floor after lunch" (T2, age 27, 3 years work experience). Apart from that, five out of thirteen trainers being interviewed found that some behavioral strategies were effective in influencing the PWD's food behaviors, for example by using the persuasive method or story-telling technique. This trainer gave an example " finish the vegetables...those who don't eat vegetables, their teeth will drop and become ugly' hah...they start to try eating the greens?' (T3, age 47, 5 years work experience).

\section{Theme 3: Nutrition teaching towards PWD}

The trainers $(n=4)$ described that they tried to deliver somewhat simple nutrition information to the PWD. One trainer mentioned she taught them by using flashcard and story-telling technique, "Boboiboy (a cartoon character) likes to drink milk, so he is strong?' (T2, age 27, 3 years work experience). Another trainer (T3, age 47, 5 years work experience) tried to teach the PWD to identify healthy and unhealthy food first and then assigned homework to color the healthy food. Besides, a few trainers $(n=3)$ also involved the PWD during meal preparation at the CBR centers. They felt that this hands-on practice would be more effective and could directly instill the nutrition knowledge in the PWD, as one of them mentioned "Every day we cook here...we assign two students to help us... at the same time we teach and monitor them...maybe at home she will follow the same thing" (T2, age 27, 3 years work experience).

\section{Theme 4: Physical activities of PWD}

Besides implementing the positive nutrition practice, the trainers described that they also increased the physical activities of PWD. Majority of the trainers $(n=7)$ had increased the frequency of exercise session from once a week to three times a week, with every session lasted between 30 minutes to 1 hour.

\section{Discussion}

Findings from the current study demonstrated that the nutrition module intervention had produced significant improvements in nutrition knowledge and practice and insignificant yet higher attitude score in intervention group as compared to comparison group during the first one month follow-up assessment. Sig- 
nificant difference in attitude score could hardly be detected at this time frame as both groups had parallel increment in attitude scores and the difference between two groups became smaller. The increment of attitude score in comparison group might be due to their increased health awareness following the training on PWD general health issues. Most favorably, the improvement of nutrition knowledge, attitude and practice scores in intervention group was significantly sustained over a period of six months after intervention and this confirmed the effectiveness of the intervention.

In conjunction with the above observations, findings on the 'reaction' of trainers in intervention group also presented a positive outcome as majority of them were highly satisfied with the program. Similar remark had been highlighted by Gerstein et al. (2010) [15] and Westergren (2012) [16] who attributed their success of nutrition interventions to the participants' satisfaction and perceived emotional safety during the program. Program that leads to good satisfaction in participants is generally promising as they are most probably interested and have high motivation to learn.

The Level 2- Learning of Kirkpatrick's model with respect to the improvement in nutrition knowledge and attitude following intervention was assessed by incorporating a comparison group. This quasi-experimental study design reflected the reward of a community-based research. The attractiveness is it does not require the randomization of participants into intervention or control group while at the same time it can protect against threats to validity. In present study, the comparison group involved the trainers from CBR centers in a different region- Terengganu. The reason for such selection was to reduce risk of contamination. If both intervention and comparison groups were selected from the same region, contamination might occur when trainers in the comparison group exposed to nutrition knowledge taught in the module training for the intervention group. In this study, no significant baseline difference in nutrition knowledge, attitude and practice as well as socio-demographic characteristics was observed between the two groups, except for the work experience which was significantly higher in the comparison group. Controlling this factor during analysis of intervention effects was definitely appropriate in obtaining a credible result. Nevertheless, there was opinion stating that a concurrent control group design is not acceptable to community members as every individual who is eligible should have the chance to receive the training [17]. As the investigator valued the idea that incorporating a control area is important to imply whether the change observed in the intervention is actually ascribable to the intervention or not [18], a wait-list comparison group was thus included in this study and they were only provided the nutrition education after the study.

Apart from that, considering the argument with regard to the inaccuracy of self-reported practice to assess the effectiveness of intervention [19-21], the mixed methods design used to evaluate the Level 3- Behavior in this study was deemed suitable. Adoption of such methodology is believed to produce findings with greater reliability and validity as one method can corroborate, enhance or clarify the findings of the other [22]. This mixed methods design was also employed by Westergren (2012) [16] to assess the effectiveness of an action-oriented nutrition program for care providers in nursing homes. In this present study, the findings from the qualitative interviews confirmed those being assessed in the practice domain of KAP-nOKU. Moreover, additional information concerning the trainers' on-the-job practice such as teaching nutrition to PWD was also obtained from the qualitative interviews. Qualitative research is said to be able to yield a deeper exploration on the issue studied [23]. In fact, mixed methods design can gain a thorough picture of a phenomenon.

In order to result in positive changes in nutrition knowledge, attitude and practice, a nutrition intervention program should have an adequate implementation period [24]. A general 10 to 15 hours implementation period was known to be sufficient to yield positive outcomes of nutrition training targeted at caregivers and other health care providers [25-27]. In view of the heavy workload and time constraint of CBR trainers, this nutrition module intervention which was designed for a three-day program covering at least 18 hours of training was considered adequate. Moreover, the intensity of this training which was conducted in three consecutive days might have unique implication as the trainers could concentrate and relate the knowledge gained from day to day and also with their workplace conditions. Intensity of training has been shown to positively associate with changes in nutrition practice [28]. In this current study, the first post-intervention assessment was done at one month after intervention while the second assessment at six months apart. Choosing this six-month interval was to allow the trainers with adequate time to apply the nutrition strategies in the CBR centers $[15,29]$. In contrast to Pawala et al. (2009) [28], no reinforcement of nutrition information was given to trainers in intervention group within these six months as the investigator wished to explore the maintenance effect of the nutrition intervention.

The effectiveness of this nutrition intervention could be attributable to the components of module which were culturallyoriented, learner-centered and behaviorally-focused [26,27]. As mentioned by Sim and Radloff (2008) [30] and Gerstein et al. (2010) [15], learning that emphasizes the social and cultural aspects is beneficial in making learning an authentic and meaningful experience which can further enhance the engagement of learners. The nutrition information (Figure 1) generated from basic to specific was relevant to facilitate a constructive learning process in a structured manner in trainers, which perhaps led to the significant advancement in trainers' knowledge and attitude. Furthermore, incorporating suitable and innovative educational materials in the program enhanced the trainers' attention and comprehension. These visual aids together with explanations can strengthen the memory better than text alone. In addition, the integration of interactive learning activities for instances the group discussions and cooking session was valuable to support learning as these activities reflected the trainers' on-the-job practices that could be applied in everyday situations $[15,30]$. The significant improvement of nutrition practice among trainers in intervention group might be traceable to these elements as these elements have been reported to increase the acceptance of nutrition messages among participants and at the same time encourage them to put the knowledge into practice $[15,27]$.

Several limitations of the study are acknowledged. Firstly, the sample size for this intervention study was relatively small. Nevertheless, it had included all rehabilitation centers in Kelantan and Terengganu and only one trainer representative from each center was allowed to join the study upon permission of the authority. Secondly, no formal need assessment was conducted among CBR trainers during nutrition module development to explore the specific content suitable for the trainers. Moreover, the nutrition 
module was not field-tested among potential participants before it was implemented in the intervention study. This might affect the effectiveness of the program as content refinement was not accomplished. Besides, the same investigator conducted the nutrition intervention as well as the qualitative interviews. This existing relationship between investigator and trainers may potentially lead to trainers giving perceived desired responses during qualitative interviews.

\section{Conclusion}

The nutrition education towards trainers in CBR centers using "Nutrition Module for Trainers with Persons with Disabilities" was unique as this program had successfully produced positive impact on improving the knowledge, attitude and practice in disease-specific nutrition management for PWD. It was a community engagement research that targeted at the natural change agent for the disability population and at the same time addressed the nutrition issues in their natural environment. Thus, it would be ideal to expand this nutrition program to various target groups who serve the disability population in whole Malaysia, for instances, the teachers or care providers in special education schools, early intervention and rehabilitation centers for children with special needs or undergraduate students from various related programs like social work, special education, occupational therapy or nursing. In addition, future studies to assess the translation of the above observed positive outcomes into better nutritional status, health and overall quality of life of PWD, are recommended.

\section{Acknowledgement}

The authors would like to thank all trainers from CBR centers in Kelantan and Terengganu who participated in the study. Special thanks to the Malaysia Department of Social Welfare and CBR centers authorities for approving the study as well as the research team and assistants for their help during the course of intervention. Finally, the authors' gratitude goes to Universiti Sains Malaysia Research University Grant (1001/PPSP/812049) and Postgraduate Research Grant Scheme (1001/PPSK/8144001) for funding the study.

\section{References}

[1]. WHO. (2011) World Report on Disability. Geneva, Switzerland.

[2]. Mikulovic J, Marcellini A, Compte R, Duchateau G, Vanhelst J, et al. (2011) Prevalence of overweight in adolescents with intellectual deficiency. Differences in socio-educative context, physical activity and dietary habits. Appetite 56(2):403-7.

[3]. Velez JC, Fitzpatrick AL, Barbosa CI, Diaz M, Urzua M, et al. (2008) Nutritional status and obesity in children and young adults with disabilities in Punta Arenas, Patagonia, Chile. Int J Rehabil Res 31(4):305-13.

[4]. Lin PY, Lin LP, Lin JD (2010) Hypertension, hyperglycemia, and hyperlipemia among adolescents with intellectual disabilities. Res Dev Disabil 31(2):545-50.

[5]. Slevin E, Truesdale-Kennedy M, McConkey R, Livingstone B, Fleming P (2012) Obesity and overweight in intellectual and non-intellectually disabled children. J Intellect Disabil Res.

[6]. Rimmer JH, Yamaki K, Lowry BM, Wang E, Vogel LC (2010) Obesity and obesity-related secondary conditions in adolescents with intellectual/ developmental disabilities. J Intellect Disabil Res 54(9):787-94.

[7]. Bhaumik S, Watson JM, Thorp CF, Tyrer F, McGrother CW (2008) Body mass index in adults with intellectual disability: Distribution, associations and service implications: A population-based prevalence study. J Intellect Disabil Res 52(4):287-98

[8]. Melville CA, Hamilton S, Hankey CR, Miller S, Boyle S (2007) The prev- alence and determinants of obesity in adults with intellectual disabilities. Obes Rev 8(3):223-30.

[9]. Wong CW (2011) Adults with intellectual disabilities living in Hong Kong's residential care facilities: A descriptive analysis of health and disease patterns by sex, age, and presence of Down syndrome. Journal of Policy and Practice in Intellectual Disabilities 8(4):231-8.

[10]. Chen ST, Soo KL, Azriani AR, Van Rostenberghe H, Sakinah H (2013) Malnutrition and its risk factors among persons with disabilities in Malaysia. Ann Nutr Metab 63(suppl 1):869.

[11]. San Turgay A, Sarı D, Türkistanlı EÇ (2005) Knowledge, attitudes, risk factors, and early detection of cancer relevant to the schoolteachers in İzmir, Turkey. Prev Med 40(6):636-41.

[12]. Natale R, Scott SH, Messiah SE, Schrack MM, Uhlhorn SB, et al. (2013) Design and methods for evaluating an early childhood obesity prevention program in the childcare center setting. BMC Public Health 13(1):78.

[13]. Chen ST, Soo KL, Ab Rahman A, Van Rostenberghe H, Harith S (2013) Development and pilot testing of nutrition knowledge, attitude and practice questionnaire in persons with disabilities (KAP-nOKU) among trainers in rehabilitation centres, Malaysia. Pak J Nutr 12(8):708-14.

[14]. Kirkpatrick DL, Kirkpatrick JD (2007) Implementing the four levels: A practical guide for effective evaluation of training programs. San Francisco: Berrett-Koehler Publishers.

[15]. Gerstein DE, Martin AC, Crocker N, Reed H, Elfant M, et al. (2010) Using learner-centred education to improve fruit and vegetable intake in California WIC participants. J Nutr Educ Behav 42:216-24.

[16]. Westergren A (2012) Action-oriented study circles facilitate efforts in nursing homes to "Go from feeding to serving": Conceptual perspectives on knowledge translation and workplace learning. Journal of Aging Research.

[17]. Bazzano AT, Zeldin AS, Diab IR, Garro NM, Allevato NA, et al. (2009) The Healthy Lifestyle Change Program: A pilot of a community-based health promotion intervention for adults with developmental disabilities. Am J Prev Med 37(6S1):S201-S8.

[18]. Walsh CM, Dannhauser A, Joubert G (2003) Impact of a nutrition education programme on nutrition knowledge and dietary practices of lower socioeconomic communities in the Free State and Northern Cape. S Afr J Clin Nutr.

[19]. Burden T, Sheeshka J, Hedley M, Lero DS, Marsh S (2000) Development, implementation, and evaluation of a nutrition education program for informal (unlicensed) child caregivers. J Nutr Educ 32(2):104-10.

[20]. Horodynski MAO, Hoerr S, Coleman G (2004) Nutrition education aimed at toddlers: A pilot program for rural, low-income families. Fam Community Health 27(2):103-13.

[21]. Freedman MR, Alvarez KP (2010) Early childhood feeding: Assessing knowledge, attitude, and practices of multi-ethnic child-care providers. J Am Diet Assoc 110(3):447-51.

[22]. Harris JE, Gleason PM, Sheean PM, Boushey C, Beto JA, et al. (2009) An introduction to qualitative research for food and nutrition professionals. J Am Diet Assoc 109:80-90.

[23]. Elo S, Kyngäs H (2008) The qualitative content analysis process. J Adv Nurs 62(1):107-15

[24]. Mohd Shariff Z, Bukhari SS, Othman N, Hashim N, Ismail M, et al. (2008) Nutrition education intervention improves nutrition knowledge, attitude and practices of primary school children: A pilot study. Int Electron J Health Educ 11:119-32.

[25]. Klohe-Lehman DM, Freeland-Graves J, Anderson ER, McDowell T, Clarke KK, et al. (2006) Nutrition knowledge is associated with greater weight loss in obese and overweight low-income mothers. J Am Diet Assoc106(1):65-75.

[26]. Kabahenda M, Mullis RM, Erhardt JG, Northrop-Clewes C, Nickols SY (2011) Nutrition education to improve dietary intake and micronutrient nutriture among children in less-resourced areas: A randomised controlled intervention in Kabarole district, western Uganda. S Afr J Clin Nutr 24(2):838.

[27]. Inayati DA, Scherbaum V, Purwestri RC, Wirawan NN, Suryantan J, et al. (2012) Improved nutrition knowledge and practice through intensive nutrition education: A study among caregivers of mildly wasted children on Nias Island, Indonesia. Food Nutr Bull 33(2):117-27.

[28]. Palwala M, Sharma S, Udipi SA, Ghugre PS, Kothari G, et al. (2009) Nutritional quality of diets fed to young children in urban slums can be improved by intensive nutrition education. Food Nutr Bull 30(4):317-26.

[29]. Ruzita AT, Fatimah A, Yong KL, Roslee R, Idris MN (2000) Penilaian pakej video sebagai alat pendidikan pemakanan di kalangan kanak-kanak sekolah rendah yang mengalami lebihan berat badan dan obesiti. Journal of Malaysia Social Health. 18:1-5.

[30]. Sim J, Radloff A (2008) Enhancing reflective practice through online learning: Impact on clinical practice. Biomed Imaging Interv J 4(1):e8. 